UDK: 811.112.2'373.7:659.131.2; 659.131.2(430):81'42

\title{
FRAZEMI U REKLAMNIM TEKSTOVIMA
}

\author{
ALMA HALIDOVIĆ 1 \\ Univerzitet u u Tuzli, Filozofski fakultet, \\ Odsjek za njemački jezik i književnost, \\ Tuzla, Bosna i Hercegovina
}

Zbog stalnog prisustva masovnih medija, reklame su usko vezane za našu svakodnevnicu, bilo da su u pitanju televizija, radio ili pak štampani mediji. Stoga nikako ne začuđuje da su reklamni tekstovi sve više omiljena tema lingvističkih istraživanja. To područje obuhvata sve nivoe jezika (npr. frazeologiju, tvorbu riječi, ortografiju). Cilj ovog rada je da se detaljnije pozabavi frazemima i da se prikažu njihove značajne jezičke karakteristike. Konkretan zadatak rada je analiza sintaksički modificiranih frazema u reklamnih tekstovima.

Ključne riječi: reklamni oglas, frazem, modifikacija, komercijalna propaganda, supstitucija, koordiniranje.

\section{UVOD}

Opterećenost konzumenata medija reklamnim informacijama raste svake godine zbog osnivanja sve više novih kompanija i društava, kao i zbog toga što se razvijaju novi mediji, ali interes konzumenata za medije i reklamu ne raste shodno tome. 0 opterećenosti i zasićenosti konzumenata informacijama putem najvažnijih medija svjedoče podaci koje navode studije iz ove oblasti: zasićenost radijskim informacijama iznosi čak $99 \%$, televizijskim informacijama $97 \%$, a zasićenost informacijama putem magazina i novina iznosi $94 \%$, odnosno $92 \%$. Navedeni podaci nam jasno govore da informacije koje bivaju plasirane putem medija u malom procentu dopiru do konzumenata, te ne postižu željeno djelovanje na sociopsihološkom polju tj. ne utiču u dovoljnoj mjeri na formiranje podsvijesti konzumenata. Vrlo mali broj informacija ( $1 \%$ -8\%) čitaoci, doslovno preplavljeni porukama masovnih medija, danas uopšte uspiju primijetiti ili pravilno protumačiti (Kroeber-Riel 1993: 14)².

Ovakvi statistički podaci o prijemu i usvajanju reklamnih informacija dovoljno su dobar izgovor za tvorce reklamnih tekstova da posegnu za jezičkim sredstvima

1 Kontakt podaci (Email): alma_husamovic@yahoo.com

2 Detaljne podatke 0 analizi zasićenosti konzemenata informacijama vidi kod Kreber-Ril (1993). 
koja istovremeno na najbolji način prenose poruku, ali i značajno utiču na kupovno ponašanje i formiranje podsvijesti konzumenata.

0 važnosti uspješnog djelovanja na konzumenta putem reklame govori i etimologija njemačkog glagola werben. Ovaj glagol svoje korijene nalazi još u glagolu werban iz srednjovisokonjemačkog koji je prvenstveno značio ,okretati se, truditi se'. Pri tome se kod okretati se misli na kretati se tamo-ovamo, truditi se oko nekoga, pridobiti nekoga za neki posao, a što i jeste suština svake reklame (Janich 1999: 16). ${ }^{3}$

0 postojanju moderne reklame, bar za njemačko područje, može se govoriti tek nakon 1850. godine čijem je naglom usponu doprinijela industrijska revolucija sa svojom masovnom proizvodnjom i masovnim društvom.

Tako Sovinski (Sowinski 1979: 9) pod reklamom, i to posebice reklamnom ekonomskom propagandom, smatra namjerni ili neuvjetovani oblik manipulisanja ili djelovanja koji ljude uz pomoć posebnih komunikacijskih sredstava treba da navede na ispunjavanje reklamnih ciljeva.

\section{KARAKTERISTIKE JEZIKA REKLAME}

Pisci reklamnih poruka shodno ciljnoj grupi konzumenata koriste određene jezične varijetete (dijalekte, sociolekte itd.) ne bi li na taj način podstakli konzumente da se identifikuju sa reklamnom porukom i ujedno pozitivno ocjenili reklamirani proizvod.

Često jezičko sredstvo u jeziku reklame jesu stručni termini. Oni se ovdje ne koriste da bi imenovali jasno i precizno određene sadržaje, što im je osnovna svrha postojanja u stručnim tekstovima, već samo da izazovu efekat prividnog znanstvenog autoriteta (usp. Janich 1999: 153). ${ }^{4}$

Za organizovanje reklamnih tekstova od velikog su značaja inovativnost i jezička kreativnost. Danas konzumenti slabije reaguju na "obične" reklame, tj. na one reklame koje u sebi ne sadrže određenu "dozu iznenađenja" i koje konzumente ne tjeraju na dalja razmišljanja o samoj poruci. Spomenuta inovativnost i kreativnost velikim dijelom utiču i na korištenje dobro odabrane leksike u oglasima. Riječi tvorene po uobičajenim i poznatim modelima tvorbe riječi ne izazivaju dovoljno pažnje prilikom čitanja oglasa, ne „intrigiraju“ konzumente u dovoljnoj mjeri. Pisci reklamnih tekstova uvidjeli su potrebu za stvaranjem reklamnih slogana i tekstova koji s tačnom namjerom krše jezičke norme. Stoga reklamne tekstove karakteriše neobičnost, komičnost, upadljivost, kratkoća i sažetost izraza te laka razumljivost. Problematičnost se ovdje krije u održavanju ravnoteže između noviteta u samoj tvorbi i jasnoće i razumljivosti samog reklamnog oglasa. Nadovezujući se na ovu problematiku Krig naglašava da „što je kreativnija i neobičnija reklamna poruka, to je ona interesantnija, ali se i primatelju poruke čini više stranom, (....)", tj. prevelika doza kreativnosti može dovesti u pitanje samu mogućnost razumijevanja poruke (Krieg 2005: 97).

3 Sovinski (Sowinski 1979:12) zastupa zanimljiv i pomalo neobičan stav o počecima reklame te navodi biblijsku priču o Adamu i Evi i zmiji koja uspijeva da ih nagovori na konzumiranje zabranjenog voća i time na neposlušnost Bogu.

4 Samo formalno stručni termini čitateljima reklamnih poruka treba da simboliziraju navodnu stručnost, dugogodišnje iskustvo, internacionalni ugled komapnije/proizvoda. 


\section{PREDMET ISTRAŽIVANJA}

Korpus ovog istraživanja čine modifikacije prikazane na 178 frazema u reklamnim oglasima prikupljenih u po 4 izdanja njemačkih časopisa "Spiegel", „Freundin" i „Brigitte". Tematika časopisa „Spiegel” obuhvata značajna područja od politike preko ekonomije, zdravlja, nauke, tehnike sve do sporta i društvenih zbivanja. Prvenstveno je namijenjen muškoj publici visokog stepena obrazovanja. To se ogleda u izboru prezentiranih oglasa, jer su pretežno prisutne reklame za automobile, kompjutere, muške satove, žestoka alkoholna pića itd. Ženski magazini „,Freundin“ i „Brigitte“ (izlaze dva puta mjesečno) jesu magazini iz oblasti mode, kozmetike i stila življenja. Popularni njemački časopisi za žene „Freundin" $i$ „Brigitte" namijenjeni su sredovječnim osobama ženskog spola. Oba magazina sadrže upadljivo velik broj reklama za parfeme, nakit, kozmetiku i odjevne predmete. Može se zaključiti da je organizacija oglasa u njima primarno vizuelno orijentisana. Rezultati analize frazema su zbog ograničenog obima rada u nastavku prikazani u sažetoj formi.

\section{FRAZEMI KAO REKLAMNA SREDSTVA}

Iako za njemačko govorno područje postoji relativno bogata literatura o frazemima, upotreba termina samog pojma frazem nije ujednačena. Termini koji se koristi za označavanje tzv. ustaljenih jedinica jedinstvenog značenja jesu Phraseologismus, Phraseolexem, phraseologische Wendung, feste Wendung, Idiom, idiomatische Wendung. Mi ćemo u ovom radu koristiti $\mathrm{b} / \mathrm{h} / \mathrm{s}$ termin frazem. On se u najširem smislu definiše kao širi pojam za sve sintagme i izreke koje se strukturno i pragmatički odlikuju po svom sastavu (sastoje se od najmanje dva elementa) te po relativnoj stabilnosti (Janich 1999: 118).

Frazemi u reklamama sa svojim širokim spektrom upotrebe spadaju u omiljena jezička sredstva te se čas koriste u frazeološkom čas u doslovnom smislu, čas sa ilustracijama čas bez njih. U frazeologiji se o frazemima govori kao o mentalnom leksikonu nekog jezika (Palm 1997: 1), jer ih govornici jedne jezičke zajednice pamte u svom mentalnom leksikonu i reproduciraju kao jednu cjelinu. Efikasnost frazema temelji se na činjenici da jednom ostvarena veza između ponuđenog proizvoda i konzumenta prelazi u trajnu asocijaciju, efikasnu manipulaciju, povezujući frazem sa odgovarajućim proizvodom.

Druga njihova značajna karakteristika jeste slikovitost. Tako se npr. kod frazema jemandem die Ohren langziehen nameće slika osobe koja drugu osobu nasilno vuče za uši. Navedeni primjer ukazuje na jezički aspekt frazema, ali i na njegov senzorni aspekt. Ovo obilježje se u oglasima koristi upravo radi spajanja reklamiranog proizvoda, njegove vizualne strane i jezičke informacije (Hagmann/Hartmann 1998: 48).

\section{MODIFIKACIJA FRAZEMA}

Poznato je da kod većeg broja frazema postoji mogućnost izvršavanja formalnih promjena bez izmjene cjelokupnog značenja frazema. Odstupanja koja odgovaraju 
uobičajenim formulacijama navedenim u leksikonu nazivaju se varijacije frazema $\mathrm{npr}^{5}$. null/ keinen Bock auf etw. haben. Kreativne i upadljive forme frazema koja se razlikuju od oblika fiksiranih leksikonom Hemi (1994: 46) ${ }^{6}$ smatra modifikacijama frazema. Poteškoće koje se ovdje javljaju tiču se problematičnosti razdvajanja varijacija frazema od njegovih modifikacija. ${ }^{7}$

Praksa je pokazala da neki frazemi vremenom gube neke svoje izvorne sastavnice te da one bivaju zamijenjene novim (usp. Jozić et al. 2006: 163). Ove namjerne i strateški ciljane izmjene na elementima frazema naročito čestu primjenu nalaze u kreativnim $i$ manipulativnim tekstovima reklamne branše.

Prikupljene primjere ćemo analizirati isključivo na nivou sintaksičke mogućnosti modifikacije koje predlaže Balzlimke (2001). Od velikog značaja za analizu frazema bila je sljedeća tipologija modifikacija koju nalazimo kod Balzlimke (2001: 68-78): lexikalische Substitution (leksička supstitucija), Erweiterung (leksičko proširivanje), Determinativkomposition (determinativne složenice), Verkürzung (skraćivanje), Koordinierung (koordiniranje), Wechsel von der Affirmation zur Negation und umgekehrt (prelazak sa afirmacije na negaciju), Häufung oder Verdichtung (nagomilavanje frazema) und Kontamination (kontaminacija). Cilj nam je bio da na osnovu zabilježenih frazema prikažemo učestalost upotrebe pojedinih vrsta frazema te da ukažemo na kreativnost reklamnih oglasa s naglaskom na analizu modifikacija na frazemima, te da na kraju izvedemo kvantitativne i kvalitativne zaključke.

\section{ZASTUPLJENOST FRAZEMA U REKLAMAMA}

Analiza primjera frazema prikupljenih iz tri navedena časopisa pokazala je sljedeće: od ukupnog broja reklamnih oglasa (178) 34,44\% ne sadrže nijedan frazem, dok $65,56 \%$ oglasa sadrže jedan ili više frazema. Veći dio frazema $(59,5 \%)$ ukazuje na postojanje modifikacije frazema, dok se manji dio frazema (40,5\%) koristi u izvornom i nepromijenjenom obliku. Sljedeći prikaz pokazuje dominaciju verbalnih frazema (50,55\%):

(1) Auf jeden Fall leicht zu merken, unverwechselbar und sehr anhänglich, denn ich möchte mit ihm auf die große Fahrt gehen. (Brigitte 2006)

(2) Bundeswertpapiere bringen auf Touren (Spiegel 2003).

Prilikom analize ustanovljen je, osim učestalosti nominalnih frazema, i znatan broj adverbijalnih frazema $(29,18 \%)$ :

(3) Kaufen Sie über kurz oder lang günstig ein (Brigitte 2007)

(4) Sie werden durch und durch zufrieden sein... (Spiegel 2003).

Ukupno zabilježenih 18 nominalnih frazema čine 9,22\% od ukupnog broja pronađenih frazema:

5 Palm (1997) ističe da su modifikacije instrumenti raznih stilova pisanja te da zbog toga nisu uvedene u leksikon nekog jezika.

6 Korisne informacije vezane za kontrastivno istraživanje frazema u raznim medijima nudi Hemi (1994).

7 Više o ovoj problematici razdavajanja vidi kod Burger/Buhofer/Sialm (1982). 
(5) Zu Hause in meinen eigenen vier Wänden (Freundin 2005)

(6) Mit T-DSL kein Problem! (Freundin 2006).

Frazeološki modeli $(5,1 \%)$ takođe čine često jezičko sredstvo:

(7) Strom wird sauberer. Tag für Tag (Brigitte 2006)

(8) Nichts ist spannender als Wirtschaft. Woche für Woche (Spiegel 2008)

(9) Stipendien von A bis Z. (Freundin 1997).

Prisustvo navedenih frazema a i poslovica (2,21\%), frazeoloških parova $(1,47 \%)$, frazeoloških termina $(1,1 \%)$ pokazuje da se javlja većina vrsta frazema. Posebnu grupu čine frazemi koji su novotvoreni a već imaju modificiran oblik. Takvi noviteti, kao što su:

(10) mit/auf/per Knopfdruck

(11) mit/auf/per Mausklick

nastali su prema navođenju Burgera (1998: 48) paralelno sa razvojem kompjuterske tehnologije i napredovanja na polju tehnologije.

Uprkos relativnom novitetu ovih frazema pronađeni su primjeri modifikacija:

1. proširenja pojedinačnih elemenata frazema

U prvom primjeru je frazem mit/auf/per Knopfdruck proširen atributom einzig, dok je u drugom vidljiva slična modifikacija pomoću neodređene zamjenice jedem:

(12) Lassen Sie Ihre Bilder mit einem einzigen Knopfdruck in Bildschirmgröße an Ihren Augen vorbeigleiten - untermalt von Ihrer Lieblingsmusik (Freundin 1997)

(13) Doch lassen Sie sich dadurch nicht täuschen mit jedem Mausklick geben Sie einen Befehl an ein absturzerprobtes und sicheres Betriebssystem, das auf LINUX basiert (Freundin 2006)

2. skraćivanja pojedinih elemenata frazema gdje se frazem mit/auf/per Mausklick koristi u reduciranom obliku Klick.

(14) T-Online bietet die komplette Reisewelt auf einen Klick! (Freundin 2005)

3. dvostruka modifikacija (skraćenje i proširenje) gdje je frazem mit/auf/per Knopfdruck istovremeno proširen partiklom nur, ali gdje se element Knopfdruck koristi u skraćenom obliku Knopf:

(15) Bedienen Sie Navigation, Telephon, Klima und Radio mit nur einem Knopf (Freundin 2005).

\section{VRSTE SINTAKSIČKIH MODIFIKACIJA}

Ovdje ćemo analizirati sintaksičke modifikacije frazema u oglasima prema navedenoj klasifikaciji koju navodi Balzlimke (2001). Kod većine modificiranih frazema utvrđene su sintaksičke modifikacije. Navedene vrste modifikacije u našem korpusu činile su najveći dio analiziranih primjera, dok su ostale modifikacije frazema pronađene u vrlo malom broju te ovdje nisu navođene. Uočeno je da je leksička supstitucija tehnika modifikacije koja čini najveći dio od ukupnog broja modifikacija u oglasima. Kod supstitucija se najviše javljaju pridjevske, glagolske i u malom broju nominalne komponente, npr.: 
(16) Funktionalität durch abgestimmte Komplettlösungen aus einer Hand. $<^{8}$ aus erster Hand (Spiegel 2003).

Verbalne komponente doživljavaju kreativno preformulisanje kako bi pažnju kupaca usmjerile na reklamirani proizvod kao npr.:

(17) Fahren auf eigenen Wegen < seinen eigenen Weg gehen (Freundin 2005)

(18) In Velux Dachwohnfenstern ist alles ruck, zuck eingebaut. < etw. geht ruck zuck (Freundin 2006).

Moguće objašnjenje za učestalu upotrebu supstitucija je eventualno neiscrpnost vrsta modifikacije za upečatljive igre riječima.

Vrlo produktivna je i metoda skraćivanja (njem. Verkürzung) dijelova frazema, kao npr.:

(19) Das Juwel für Ihr Vermögen. < ein Juwel sein (Freundin 2005)

(20) Lust auf Schiff? < Lust haben auf etw. (Brigitte 2002).

Jezička ekonomičnost koja je karakteristična za jezik reklame moguće je objašnjenje za ovu vrstu modifikacije. Suprotno tendenciji skraćivanja oblika frazema prisutan je i princip leksičkih proširenja. Obično ne dolazi do promjene značenja frazema nego se značenje frazema samo ograniči ili prilagodi konkretnom oglasu određenog proizvoda, npr.:

(21) Sie ergänzen sich gegenseitig, leuchten und geben ihm den perfekten, glänzenden letzten Schliff. < einer Sache den letzten Schliff geben (Freundin 2006)

(22) So werden Sie Ihren Alten auf bequeme Art und Weise los - und schlagen gleichzeitig Profit daraus < die Art und Weise (Spiegel 2003).

Proširenja frazema mogu se pojaviti u obliku determinativnih složenica (njem. Determinativkomposita) kao npr.:

(23) Denn Apple hat das Werkzeug, um Digitalbilder auf eine völlig neue Weise zu speichern ... < das Zeug zu etw. haben (Freundin 2005) 1997).

(24) Am besten, Sie gehen gleich auf Schatzsuche. < auf die Suche gehen (Freundin

Posljedica prelaska sa afirmacije na negaciju (njem. Wechsel von der Affirmation zur Negation)i obrnuto može biti supstitucija, skraćivanje ili proširenje što može izazvati efekt „ponavljanja” ili „umanjenja značenja” sadržaja frazema (Burger/Buhofer/Sialm 1982:79); ${ }^{9}$

(25) Eine Geburt ist kein Kinderspiel. < ein Kinderspiel sein (für jdn.) (Freundin 2006)

(26) Wer große Sprünge machen will, braucht die richtigen Anlagen. < keine großen Sprünge machen (können) (Spiegel 2002)

(27) Ich fühl mich wohl in meiner Haut < sich (jdm. gegenüber) nicht wohl in seiner Haut fühlen (Freundin 2005).

U korpusu oglasa za modifikaciju pomoću korištenja razdvajanja frazema zabilježeno je malo primjera. Zabilježeni su sljedeći osnovni principi: razdvajanje se izvrši u jednoj te istoj rečenici ili se komponente frazema podijele na dvije odvojene rečenice, npr.:

8 Ovim znakom upućuje se na izvorni frazem koji je poslužio kao model za izvršenje modifikacije.

9 Navodi se da ova metoda modifikacije ima funkciju posebnog naglašavanja te da se zbog svog pretežno jakog efekta ne koristi često (usp. Burger/Buhofer/Sialm 1982: 79). 
(28) Auch in Spanien gibt es Wege, die nach Rom führen. < Viele Wege führen nach Rom (Spiegel 2003)

(29) Unter guten Bedingungen wächst Gras in einer Woche ca. 8 Milimeter. Können Sie es hören? < das Gras wachsen hören (Freundin 2005) 2006).

(30) Es gibt Pro. Es gibt Contra. Und es gibt Sie. < das Pro und Contra/Kontra (Freundin

Poteškoće kod koordiniranja često stvara nejasnoće kod uočavanja ili prepoznavanja frazema. Nije jasno prepoznatljivo da li su pisci reklamnih oglasa koristili obične riječi koje mogu biti sastavni dio frazema ili su pak koordinirano koristili dva frazema, npr.:

(31) Unsere Möbel und Accesessoires sollen Ihnen dabei helfen - und das zu Preisen, die allein schon gute Laune machen < guter Laune sein + Spaß machen (Freundin 2006);

(32) Bundeswertpapiere machen den Start klar. < alles klar zum Start + den Anfang machen (Spiegel 2002).

\section{ZAKLJUČAK}

Samom analizom sintaksičkih modifikacija frazema prikupljenih u reklamnim oglasima utvrđeno je da frazemi imaju znatnu važnost za organizovanje oglasa jer $65,56 \%$ analiziranih oglasa sadrži barem jedan frazem. Detaljnija analiza pokazala je da se veći dio frazema u reklamnim tekstovima javlja sa modifikacijama $(59,5 \%)$. Potvrđena je raznolikost modifikacija jer su evidentirane skoro sve vrste frazema. Analiza sintaksičkih modifikacija pokazala je da su najčešće leksičke supstitucije (38\%), skraćivanja frazema (30\%), proširenja frazema (20\%), prelasci sa afirmacije na negaciju (2\%) i koordiniranje frazema (1\%). U slučaju leksičke supstitucije dominirali su verbalni i adverbijalni frazemi. Modifikacijama frazema u komercijalnim reklamnim oglasima frazemi se na originalan način dovode u vezu sa određenim kontekstom i proizvodom ili uslugom kako bi se ostvarili određeni marketinški ciljevi.

\section{MAGAZINI}

Brigitte (juni 2006., avgust 2006., decembar 2006., april 2007., br. 13 2008.)

Freundin (br. 47 2005., br. 19 1997., br. 20 1997., br. 32 2006., br. 14 2009.)

Spiegel (januar 2003., april 2005., juli 2007., avgust 2008., br.11 2010.)

\section{LITERATURA}

Balsliemke, P. 2001. Da sieht die Welt schon anders aus. Phraseologismen in der Anzeigenwerbung. Hohengehren: Schneider Verlag.

Burger, H., A. Buhofer und A. Sialm. 1982. Handbuch der Phraseologie. Berlin: Gruyter. Burger, H. 1998. Phraseologie. Eine Einführung am Beispiel des Deutschen. Berlin: Erich Schmidt Verlag. 
Hagmann, S. und D. Hartmann. 1998. Phraseologismen in der Werbung. Beiträge zur Fremdsprachenvermittlung 33, 45-64.

Hemmi, A. 1994. Es muss wirksam werben, wer will nicht verderben. Bern: Peter Lang. Janich, N. 1999. Werbesprache. Tübingen: Gunter Narr Verlag.

Janich, N. 2005. Wenn Werbung Sprüche klopft. Der Deutschunterricht. Phraseologismen und ihre Varianten 5, 45-54.

Jozić, I., L. Pon i A. Rakovac. 2006. Pragmatički i značenjski elementi frazema u tekstnoj vrsti intervju. Jezikoslovlje 7, 153-171.

Krieg, U. 2005. Wortbildungsstrategien in der Werbung. Hamburg: Buske Verlag.

Kroeber-Riel, W. 1993. Strategien und Technik der Werbung: Verhaltenswissen-schaftliche Ansätze. Stuttgart: Kohlhammer - Edition.

Palm, C. 1997. Phraseologie. Tübingen: Gunther Narr Verlag.

Sowinski, B. 1979. Werbeanzeigen und Werbesendungen. München: R. Oldenburger Verlag.

\section{ZUSAMMENFASSUNG}

\section{PHRASEOLOGISMEN IN DER WERBESPRACHE}

Wegen des riesigen Einflusses der Massenmedien ist Werbung ist ständiger Begleiter in unserem Alltags: ob im Fernsehen, im Radio oder in der Zeitung - wir sind ständig von Werbung umgeben. Daher verwundert nicht, dass Werbetexte ein sehr beliebtes linguistisches Forschungsfeld sind. Das Interesse richtet sich auf alle sprachlichen Beschreibungsebenen (z.B. Phonologie, Wortbildung, Ortographie). Ziel ist es, Phraseologismen in Anzeigen zu untersuchen und die wesentlichen sprachlichen Charakteristika herauszuarbeiten. Das konkrete Anliegen dieser Arbeit besteht in der exemplarischen Untersuchung der syntaktisch modifizierten Phraseologismen in Werbeanzeigen.

SCHLÜSSELWÖRTER:Werbeanzeige,Phraseologismus,Modifikation, Werbepropaganda, Substitution, Koordinierung. 